\title{
The first giant titanosaurian sauropod from the Upper Cretaceous of North America
}

\author{
Denver W. Fowler and Robert M. Sullivan \\ Acta Palaeontologica Polonica 56 (4), 2011: 685-690 doi: http://dx.doi.org/10.4202/app.2010.0105
}

Argentinosaurus (Cenomanian, Argentina) is generally accepted as being the largest dinosaur so far discovered and is one of several giant titanosaurian sauropods known from the Upper Cretaceous of South America and Asia, but surprisingly not from North America. Here we present the first evidence of giant titanosaurian sauropods from the Upper Cretaceous of North America: two enormous vertebrae and a partial femur, from the Naashoibito Member of the Ojo Alamo Formation, New Mexico, and referred to Alamosaurus sanjuanensis. One of the new vertebrae, a posterior cervical, is comparable in size to a posterior cervical described for Puertasaurus: an Argentinosaurus-sized titanosaurian from the Maastrichtian of Argentina. This makes A. sanjuanensis the largest dinosaur from North America, and among the largest in the world. These findings indicate that $A$. sanjuanensis is diagnosed based on immature remains, which may have implications for cladistic analyses.

Key words: Dinosauria, Sauropoda, Titanosauria, Alamosaurus, body mass, Naashoibito Member, Ojo Alamo Formation, New Mexico, North America.

Denver Fowler [df9465@yahoo.co.uk], Museum of the Rockies, 600 W. Kagy Blvd., Bozeman, MT 59717; Robert Sullivan [rsullivan@state.pa.us], The State Museum of Pennsylvania, 300 North St., Harrisburg, PA 17120.

This is an open-access article distributed under the terms of the Creative Commons Attribution License (for details please see creativecommons.org), which permits unrestricted use, distribution, and reproduction in any medium, provided the original author and source are credited. 
FoF Full text $(218.6 \mathrm{kB})$ 